\title{
Development of Improved Wheel Friction Block with Integrated Flange Lubrication and Tread Adhesion Functions
}

\author{
Kazuyuki HANDA \\ Katsuyoshi IKEUCHI \\ Frictional Materials Laboratory, Materials Technology Division \\ Shinichi SAGA \\ Brake Control Laboratory, Vehicle Control Technology Division
}

\begin{abstract}
This paper describes the development of a wheel friction block that integrates the functions of wheel flange lubrication and tread adhesion improvement. We devised a configuration in which friction material with adhesion increasing material on the tread and material containing solid lubricant with $\mathrm{MoS}_{2}$ at the flange are applied vertically by a tread cleaning device. The developed blocks were tested for an express train in operation and traveled about $200,000 \mathrm{~km}$. As a result, the wear rate of the wheel flanges was reduced by an average of about $40 \%$ compared to the wheel flanges of vehicles not equipped with the developed blocks.
\end{abstract}

Key words: wheel, flange, wear, solid lubricant, adhesion, integral molding, lubrication

\section{Introduction}

\subsection{Background}

Wheel flange wear occurs because of contact with the outer curved rail, therefore lubrication is required to reduce wear, except on lines with few curves. Lubrication of the flange section (Fig. 1) is also important for reducing noise. Although a lubricator is often used to lubricate wheel flange sections, it cannot be used in some cases because if lubricant adheres to the wheel tread or the top of a rail, it can cause slipping or sliding. In addition, the use of a lubricator means that the lubricant must be replenished and its position adjusted when the wheel diameter changes. A device that has a stickshaped solid lubricant block in a special holder fixed to a bogie and is applied to the flange section by a spring is used overseas [1]. However, a lot of lubricant is consumed because it is in constant contact, and it also requires the position to be adjusted, and thus has the same issues as when using a lubricator.

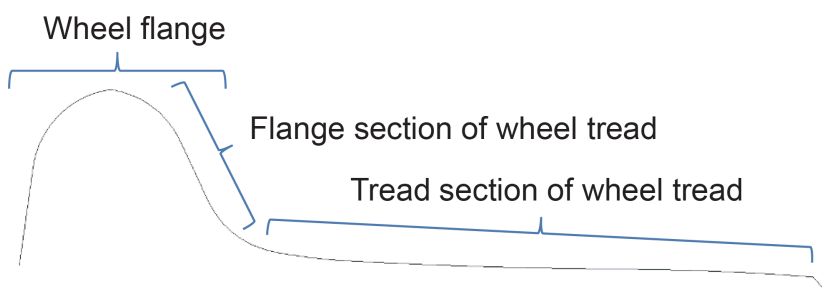

Fig. 1 Schematic of wheel tread

\subsection{Objective}

Regarding the properties required for the wheel's contact with the rail, the wheel flange section is required to have less friction and wear as described above, while the wheel tread requires removal of dirt from it and an appropriate surface roughness to ensure adhesion. To ensure adhesion of the tread, some cars are equipped with a tread cleaning device, which activates the tread abrasive block that cleans the wheel tread and produces appropriate roughness. In principle, the tread cleaning device works with the brake and applies the tread abrasive block perpendicular to the tread. If this tread cleaning de- vice is used to apply lubricant vertically to the wheel flange section, positional adjustment is not required.

Thus, we devised an improved wheel friction block, which could be attached to a tread cleaning device, integrating both wheel flange lubrication and tread adhesion functions (Fig. 2). To ensure that the solid lubricant and the tread abrasive are in contact with the wheel flange section and the tread, respectively, and to assure the reliability of the bonding interface, we chose to manufacture the solid lubricant and tread abrasive by integral molding.

The purpose of the present work is to develop an improved wheel friction block that have integrated flange lubrication and tread adhesion functions and to verify its performance when installed in actual vehicles.

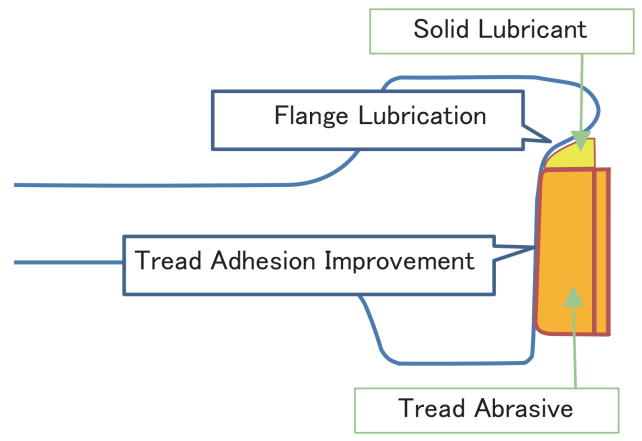

Fig. 2 Configuration of the developed wheel friction block

\section{Methodology}

\subsection{Material selection and evaluation}

The solid lubricant material was selected to ensure that the wear reduction effect and the strength of the joint interface in the integral molding were compatible, provided that it could be

integrally molded with the tread abrasive. We used molybdenum disulfide $\left(\mathrm{MoS}_{2}\right)$ and graphite $(\mathrm{C})$ as the main lubricating components.

For the wear reduction effect, we used a small rotary contact 
tester to rub a steel material equivalent to the wheels and rails in conditions close to the wheel-rail contact conditions (Table 1). In the tests a cylindrical specimen of which the diameter was set to provide the intended Hertzian stress was pressed to a rotating disc, both were made of S65C steel (Fig. 3 (a)). Solid lubricant was pressed on the rubbing trace (i.e. at the same radius) of the cylindrical specimen on the disc separately from the cylindrical specimen by a common actuator (Fig. 3 (b)(c)).

We evaluated the wear reduction effect using wear rates obtained after applying the solid lubricant. Seizure occurred with no lubrication, however, with the solid lubricant, the wear rate was $1 / 100$ or less with less wear and a smooth friction surface (Fig. 3 (d)).

\subsection{Shape design}

The developed block, attached to the tread cleaning device fixed to the bogie frame, has a structure in which the solid lubricant is placed in the part where the dimension on the flange side is enlarged compared to the tread abrasive block (Fig. 1). Its shape meets all the following conditions:

1) During slow release, the wheel is maximally displaced outward with the tread cleaning device closest to the wheel; furthermore, even if the mounting lateral gap is zero, it does not come into contact with the wheel flange section.

2) Prioritizing the wheel tread polishing function, the abrasive section comes into contact with the tread first at the beginning of use, and then the lubricant section comes into contact with the flange after the wear has progressed to some extent.

3) For wheel lateral displacement larger than the mounting gap, the contact surface with the tread surface rises to release the displacement even when the tread cleaning device is operating.

\subsection{Strength verification}

The JRS Standards of the former Japan National Railways specified the impact strength of the adhesion improvement abrasive block for cars as $2.0 \mathrm{~kJ} / \mathrm{m}^{2}$ or more. The junction interface between abrasive and solid lubricant is considered to be the most fragile structurally in the developed block. To investigate its strength, we cut it out so that one end side of the impact test piece became tread abrasive and the other became solid lubricant and conducted a Charpy impact test such that the hammer struck near the interface. The test demonstrated that the junction interface meets the standard values of the former JRS.

In addition, we repeated the contact durability test considering the situation where it is exposed to a shock load repeatedly due to the displacement of the wheelset while being pressed by the tread cleaning device during driving. Using a tread cleaning device and wheels, we placed them so that the solid lubricant section of the developed block made contact through impact with the flange section of the wheel rotating at a peripheral speed of $130 \mathrm{~km} / \mathrm{h}$, and repeatedly brought them into contact about 100,000 times. As a result, no damage was caused to the joint interface even when a frictional load accompanied by an impact was applied beyond that assumed to occur for the actual car.
Table 1 Test conditions for the wear test

\begin{tabular}{|l|l|}
\hline Sliding speed & $2 \mathrm{~m} / \mathrm{s}$ \\
\hline Nominal load & $1000 \mathrm{~N}$ \\
\hline Hertzian stress & $580 \mathrm{MPa}$ \\
\hline Test time & $10 \mathrm{~s}, 50$ times \\
\hline
\end{tabular}

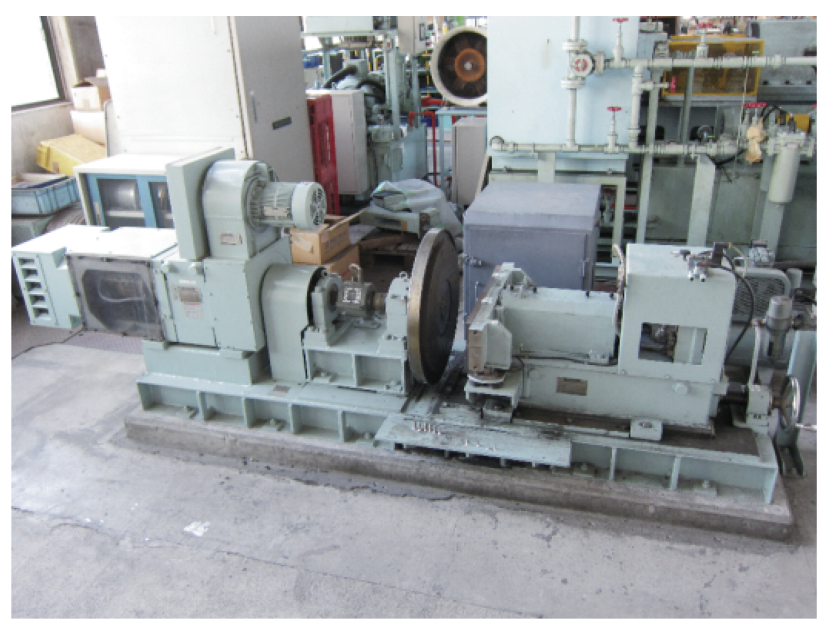

(a) The rotary contact wear tester.
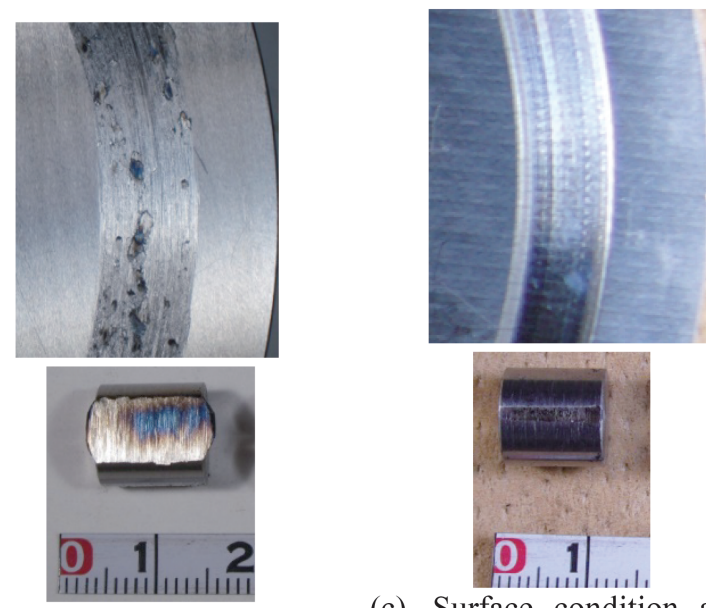

(b) Surface condition after tests without lubricant.

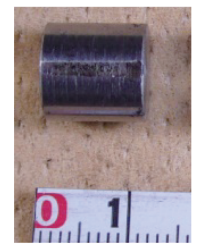

(c) Surface condition after tests with solid lubricant applied.

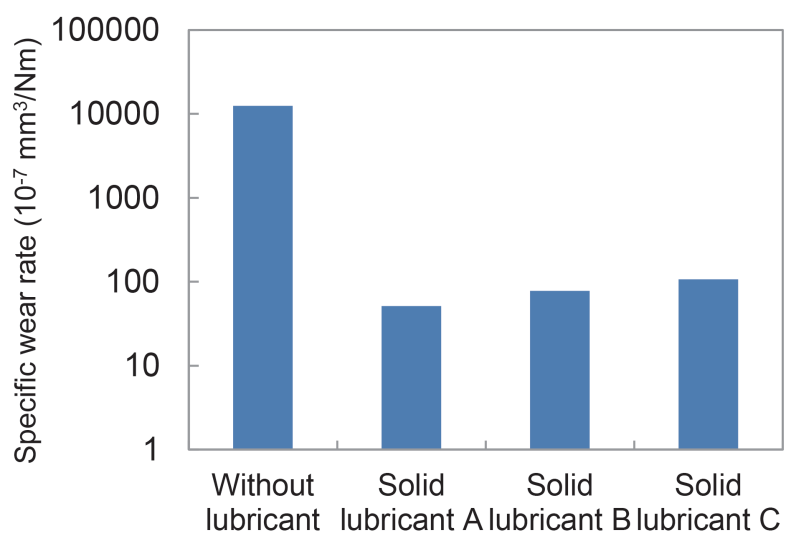

(d) Wear rate of disc specimen in the rotary wear test. 


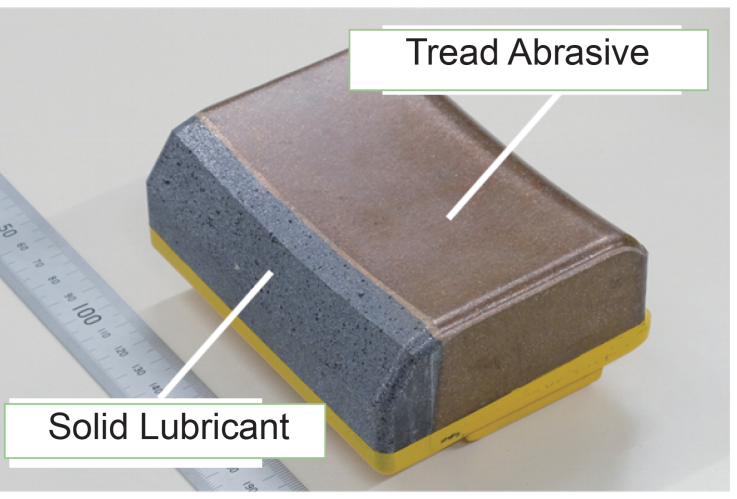

(a) Configuration of integrated tread conditioning block

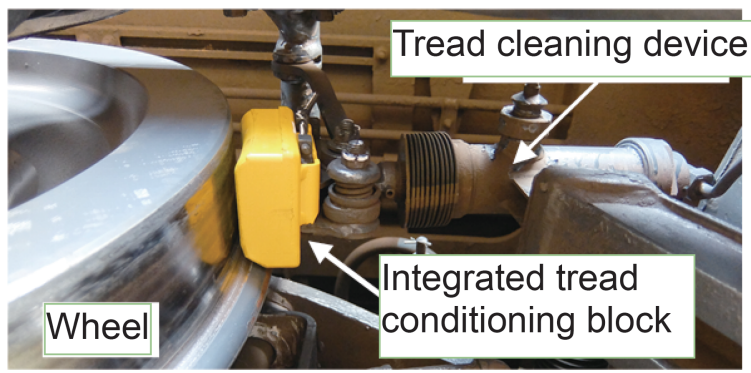

(b) Installation state in the actual car

Fig. 4 Configuration of the integrated tread conditioning block and installation on an actual car

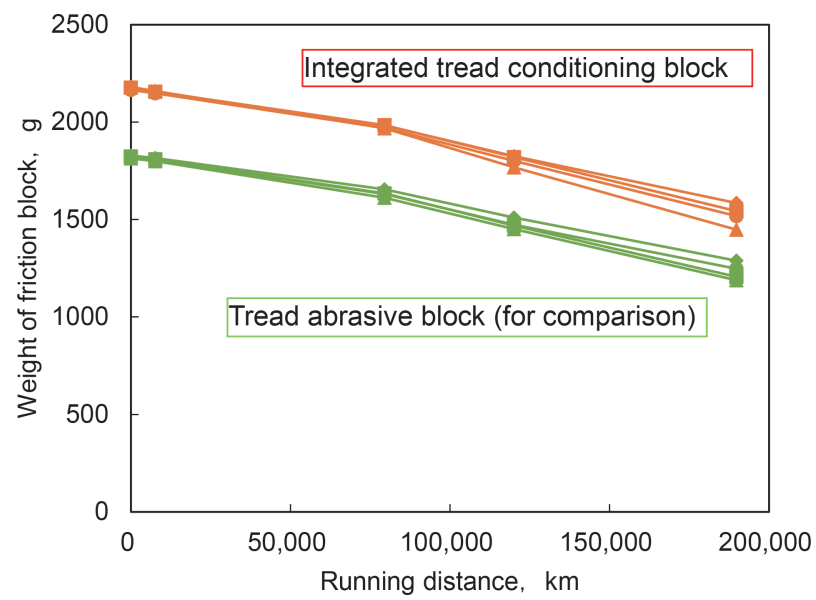

Fig. 5 Wear amount of the integrated tread conditioning block when installed on an actual car

\section{Results}

\subsection{Wear resistance of the block}

We installed the developed block (hereinafter "integrated tread conditioning block"; Fig. 4) in four locations on one bogie of a trailer car of a limited express EMU trainset on a conventional line and installed an ordinary tread abrasive block to four locations of the other bogie of the same car, then used them in commercial operations to compare the wear trends. Fig. 5 shows the results. We confirmed that the wear rates of the integrated tread conditioning block and tread abrasive block are equivalent and that the test did not cause any damage (including cracks and chips), abnormal wear, galling, etc. This shows that the integrated tread conditioning block is applicable to actual cars by the same inspection method and replacement standard as the tread abrasive block.

\subsection{Wheel wear reduction effect}

In order to verify the wear reduction performance of the wheel flange in the actual car, we installed the integrated tread conditioning block in multiple locations on a train set and, after long-term use, compared the wear tendencies obtained with the that found on cars of the same type running on the same line section at the same time. The blocks were installed in 16 different locations on both bogies on two of three trailer cars in a train set that had a tread cleaning device, and for the other trailer bogies, the existing tread abrasive block was used. Figure 5 shows the results of an evaluation of the wheel wear reduction effect, obtained by comparing the wear tendencies of the car equipped with integrated tread conditioning blocks and those of wheels on a car of the same type as the test car. The flange wear rate of the wheel in each location equipped with an integrated tread conditioning block was about $40 \%$ less than that of wheels in the same locations of the train set, without the blocks (Fig. 6).

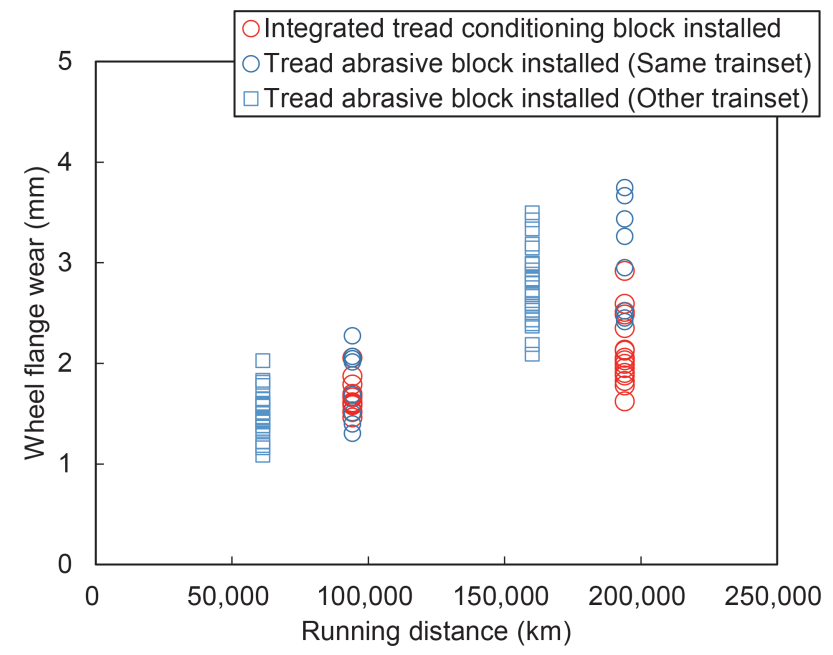

(a) Flange wear of wheels during long-term usage.

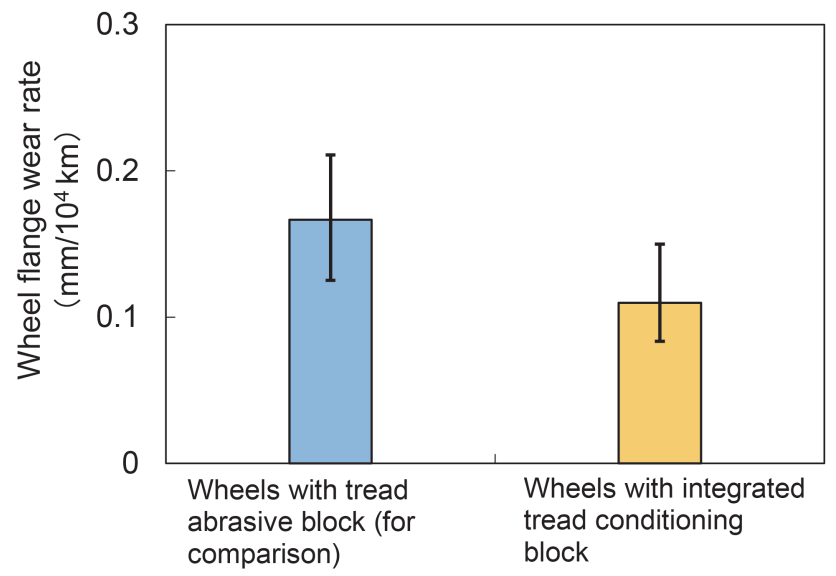

(b) Wheel flange wear rate after long-term usage.

Fig. 6 Comparison of wheel flange wear rate in actual car installation tests 


\section{Conclusion}

In order to achieve both flange wear reduction and tread adhesion improvement, we developed a new wheel tread friction block that can be mounted on the existing tread cleaning device. In the developed block, solid lubricant was positioned against the wheel flange, and proven tread abrasive material was placed against the wheel tread, and they were integrally molded.

The wear-reducing performance of solid lubricant was evaluated using a rotating wear tester reflecting the wheel/rail contact conditions and materials. The results showed that the use of the solid lubricant significantly reduces the wear.

Furthermore, the developed block was designed with a geometry giving preference to tread adhesion over flange wear. The strength of the block satisfied the standard requirements even at the bond interface, which is a weak point in strength.

We installed the developed "integrated tread conditioning blocks" in an actual trainset and tested them on long-term commer- cial services. As a result, the wear rate of the wheel flange was about $40 \%$ less than that of a vehicle without the developed block.

We have continued tests of the integrated tread conditioning block installed on actual cars and have observed stable wear reduction effects. Reduction of the flange wear rate by applying the integrated tread conditioning block extends the wheel grinding cycle and reduces the amount of wheel grinding. The wheel replacement life can be extended depending on the wheel diameter when a car enters a plant. Wheel replacement life has a significant impact on vehicle maintenance costs, and we are now assessing those cost effects.

\section{References}

[1] D. T. Eadie and R. Hui, "Wheel Life Extension With On-Board Solid Stick Flange Lubrication," Proc. 14th International Wheelset Congress, Orlando, Florida 2004.

\section{Authors}

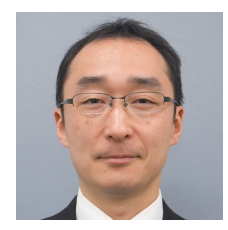

Kazuyuki HANDA, Dr. Eng.

Senior Chief Researcher, Head of Frictional materials Laboratory, Materials Technology Division

Research Areas: Frictional Materials

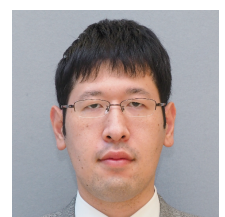

Katsuyoshi IKEUCHI, Dr. Eng.

Assistant Senior Researcher, Frictional

materials Laboratory, Materials Technology

Division

Research Areas: Frictional Materials

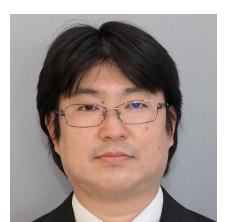

Shinichi SAGA

Senior Researcher, Brake control Laboratory, Vehicle Control Technology Division, Research Areas: Brake Control 